\title{
Chemistry in confined spaces: Reactivity of the Zn-MOF-74 channels
}

\author{
S. Zuluaga, ${ }^{1}$ E. M. A. Fuentes-Fernandez, ${ }^{2}$ K. Tan, ${ }^{2}$ C. A. Arter, ${ }^{1}$ J. Li, ${ }^{3}$ I. J. Chabal, ${ }^{2}$ and T. Thonhauser ${ }^{1, *}$ \\ ${ }^{1}$ Department of Physics, Wake Forest University, Winston-Salem, North Carolina 27109, USA \\ ${ }^{2}$ Department of Materials Science and Engineering, University of Texas at Dallas, Richardson, Texas 75080, USA \\ ${ }^{3}$ Department of Chemistry and Chemical Biology, Rutgers University, Piscataway, New Jersey 08854, USA
}

(Dated: June 15, 2021)

\begin{abstract}
Using infrared spectroscopy combined with ab initio methods we study reactions of $\mathrm{H}_{2} \mathrm{O}$ and $\mathrm{CO}$ inside the confined spaces of Zn-MOF-74 channels. Our results show that, once the water dissociation reaction $\mathrm{H}_{2} \mathrm{O} \rightarrow \mathrm{OH}+\mathrm{H}$ takes place at the metal centers, the addition of 40 Torr of $\mathrm{CO}$ at $200{ }^{\circ} \mathrm{C}$ starts the production of formic acid via $\mathrm{OH}+\mathrm{H}+\mathrm{CO} \rightarrow \mathrm{HCO}_{2} \mathrm{H}$. Our detailed analysis shows that the overall reaction $\mathrm{H}_{2} \mathrm{O}+\mathrm{CO} \rightarrow \mathrm{HCO}_{2} \mathrm{H}$ takes place in the confinement of MOF-74 without an external catalyst, unlike the same reaction on flat surfaces. This discovery has several important consequences: It opens the door to a new set of catalytic reactions inside the channels of the MOF-74 system, it suggests that a recovery of the MOF's adsorption capacity is possible after it has been exposed to water (which in turn stabilizes its crystal structure), and it produces the important industrial feedstock formic acid.
\end{abstract}

\section{INTRODUCTION}

Metal organic framework (MOF) materials are porous crystals widely studied for important applications and industrial processes such as gas storage and sequestration, 110 molecular sensing, 11,16 polymerization, $\frac{17 \mid 18}{18}$ luminescence, $\frac{1920}{120}$ non-linear optics, ${ }^{21}$ magnetic networks, ${ }^{22}$ targeted drug delivery, ${ }^{23}$ multiferroics, 24 26 and catalysis.27/30 In particular, MOF-74 $\left[\mathcal{M}_{2}\right.$ (dobdc), $\mathcal{M}=\mathrm{Mg}^{2+}, \mathrm{Zn}^{2+}, \mathrm{Ni}^{2+}, \mathrm{Co}^{2+}$, and dobdc $=2,5$-dihydroxybenzenedicarboxylic acid] has shown great potential for the adsorption of small

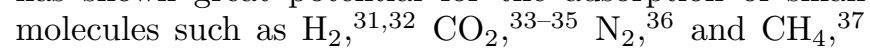
among others.

The favorable reactivity of MOF-74 has been widely studied $38 \sqrt[33]{43}$ For example, Co-MOF-74 exhibits a catalytic activity towards $\mathrm{CO}$ oxidation, $\frac{40}{-}$ originating from the high density of lewis acidic coordinatively unsaturated sites and the MOF's porosity. The inclusion of Co atoms into Ni-MOF-74 results in a mixed system $(\mathrm{Co} / \mathrm{Ni}-$ MOF-74) that shows activity towards the oxidation of cyclohexene, where the catalytic performance of the mixed system is higher than the one of pure Co-MOF-74. $\stackrel{41}{ } \mathrm{On}$ the other hand, our previous results have shown that several members of the MOF-74 family are able to catalyze the dissociation of water into $\mathrm{H}$ and $\mathrm{OH}$ groups $\left(\mathrm{H}_{2} \mathrm{O} \rightarrow \mathrm{OH}+\mathrm{H}\right.$, see Fig. 1) at low temperatures and pressures, i.e. above $150{ }^{\circ} \mathrm{C}$ and at 8 Torr of $\mathrm{H}_{2} \mathrm{O}$ This particular catalytic reaction is responsible for the loss of crystal structure and adsorption capacity after exposure of MOF-74 to water $\frac{44}{4}$ and constitutes one of the main hurdles for wide-spread applications of MOFs in general and MOF-74 in particular. This challenge has motivated our efforts to look for new catalytic reactions inside the confined channels of MOF-74, further reacting the undesirable products of the $\mathrm{H}_{2} \mathrm{O} \rightarrow \mathrm{OH}+\mathrm{H}$ reaction in order to overcome these hurdles.

In this work, we show that introducing $\mathrm{CO}$ molecules into the pores of MOF-74-after the $\mathrm{H}_{2} \mathrm{O} \rightarrow$ $\mathrm{OH}+\mathrm{H}$ reaction has taken place - enables the reaction

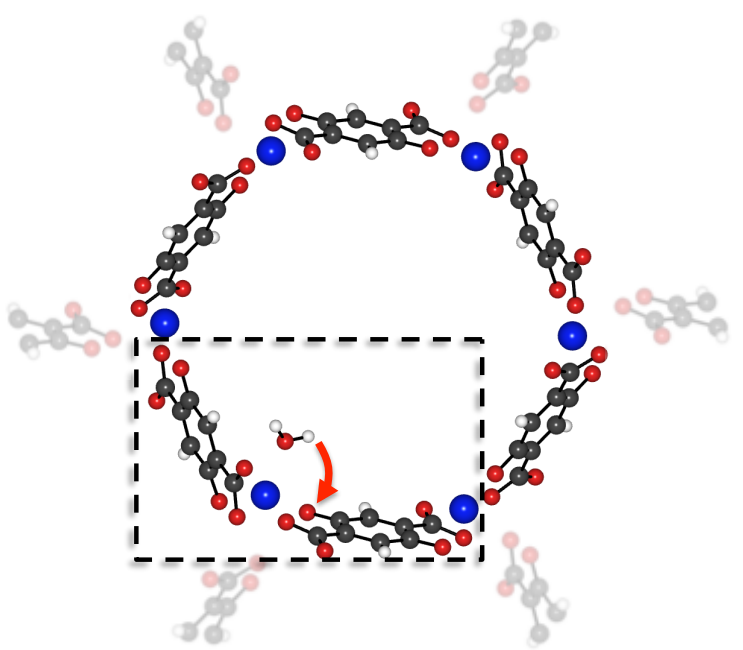

FIG. 1. Zn-MOF-74 with its hexagonal channels clearly visible. The open-metal sites at the corners form the primary adsorption sites. The arrow indicates how the $\mathrm{H}$ of the water is transferred to the $\mathrm{O}$ of the linker during the $\mathrm{H}_{2} \mathrm{O} \rightarrow \mathrm{OH}+\mathrm{H}$ reaction. Black, red, white, and blue spheres represent $\mathrm{C}, \mathrm{O}$, $\mathrm{H}$, and $\mathrm{Zn}$ atoms. The box shows the portion of MOF-74 visible in other figures, albeit from a slightly different angle.

$\mathrm{OH}+\mathrm{H}+\mathrm{CO} \rightarrow \mathrm{HCO}_{2} \mathrm{H}$. Our results show that the overall reaction $\mathrm{H}_{2} \mathrm{O}+\mathrm{CO} \rightarrow \mathrm{HCO}_{2} \mathrm{H}$ takes place in the confinement of the MOF without an external catalyst, with a number of important consequences: First, it showcases the reactivity inside the well-controlled and isolated environment of the MOF-74 channels. This aspect is very important, as the confinement of the MOF-74 environment catalyzes reactions that would otherwise require very high pressure, bringing significant simplifications for experiments and possible MOF applications. Next, it shows initial indications of a partial adsorption capacity recovery after exposure of MOF to water, as the $\mathrm{OH}$ groups that otherwise poison the metal centers are now 
bound to and removed as formic acid. In turn, it increases the crystal structure stability of MOF-74 by removing the $\mathrm{OH}$ and $\mathrm{H}$ groups that cause the instability (note that, due to their strong binding, those groups cannot be removed by thermal activation) ${ }^{44}$ And finally, it binds the toxic $\mathrm{CO}$ and produces formic acid, a nontoxic liquid with $4.4 \mathrm{wt} \%$ hydrogen and thus a promising hydrogen carrier 4751 and an important feedstock medi$\mathrm{cal} /$ industrial chemical. The use of $\mathrm{Pd}$ as catalytic material in direct formic acid fuel cells has brought interesting developments in this area,$\sqrt[52]{55}$ highlighting formic acid as a valuable asset for a hydrogen economy.

\section{EXPERIMENTAL AND THEORETICAL METHODS}

\section{A. Zn-MOF-74}

Out of the isostructural $\mathcal{M}$-MOF-74 family, Zn-MOF74 exhibits the highest catalytic activity towards the $\mathrm{H}_{2} \mathrm{O} \rightarrow \mathrm{OH}+\mathrm{H}$ reaction $\stackrel{45}{-}$ We thus use this system to study the $\mathrm{H}_{2} \mathrm{O}+\mathrm{CO} \rightarrow \mathrm{HCO}_{2} \mathrm{H}$ reaction through a combination of $a b$ initio simulations and experiments.

\section{B. Hydrogen vs. Deuterium}

Only recently, our work showed direct evidence of the water dissociation reaction $\mathrm{H}_{2} \mathrm{O} \rightarrow \mathrm{OH}+\mathrm{H}$ at the metal centers of MOF-74 above $150{ }^{\circ} \mathrm{C} ! 45 / 46$ In this reaction, the water first binds to an open-metal site and then donates one $\mathrm{H}$ to the nearby $\mathrm{O}$ at the linker; the remaining $\mathrm{OH}$ group stays at the open-metal site, see Fig. 1. Interestingly, this reaction can only be observed when heavy water $\mathrm{D}_{2} \mathrm{O}$ is used. Its fingerprint is a sharp peak at $970 \mathrm{~cm}^{-1}$ in the IR spectrum, corresponding to the $\mathrm{O}-$ D vibration at the linker $\frac{45}{6}$ When $\mathrm{H}_{2} \mathrm{O}$ is used instead, the peak appears at a higher frequency, where it couples with and is masked by the vibrational modes of the MOF and becomes impossible to detect. Therefore, the main focus of our experiments is on the water reaction with $\mathrm{D}_{2} \mathrm{O}$. We refer to the resulting deuterated formic acid as FA(D). Nonetheless, we do show that the reaction also occurs with $\mathrm{H}_{2} \mathrm{O}$, referring to the resulting formic acid as $\mathrm{FA}(\mathrm{H})$. For simplicity, throughout the text we may generally say water, even when experiments are done with heavy water.

\section{Experimental Details and Procedure}

Our experiments are divided into 3 steps:

(i) Preparation and activation of the sample: Zn-MOF-74 powder $(\sim 2 \mathrm{mg})$ was pressed onto a $\mathrm{KBr}$ pellet ( $\sim 1 \mathrm{~cm}$ diameter, $1-2 \mathrm{~mm}$ thick). The sample was placed into a high-pressure high-temperature cell (product number $\mathrm{P} / \mathrm{N} 5850 \mathrm{c}$, Specac Ltd, UK) at the focal point of an infrared spectrometer (Nicolet 6700, Thermo Scientific, US). The sample was activated under vacuum at $180{ }^{\circ} \mathrm{C}$ for 4 hours and then cooled down to room temperature to measure $\mathrm{CO}_{2}$ absorption by introducing 6 Torr of $\mathrm{CO}_{2}$ into the cell until saturation (30 minutes). Then, the area under the peak at $2338 \mathrm{~cm}^{-1}$ was determined, which is a characteristic peak of $\mathrm{CO}_{2}$ adsorbed on the $\mathrm{Zn}$ site and thus a quantitative measure of the $\mathrm{CO}_{2}$ uptake. ${ }^{56}$ Thereafter, the cell was evacuated under vacuum $(<20 \mathrm{mTorr})$ at a temperature of $150{ }^{\circ} \mathrm{C}$ for a period of 4 hours.

(ii) Dissociation reaction: The sample was heated to $200{ }^{\circ} \mathrm{C} .8$ Torr of $\mathrm{D}_{2} \mathrm{O}$ were then introduced into the cell until saturation occurred ( 8 hours) to start the dissociation reaction. Spectra were recorded as a function of time during the adsorption process to evaluate the $970 \mathrm{~cm}^{-1}$ peak, i.e. the fingerprint of the $\mathrm{D}_{2} \mathrm{O} \rightarrow$ $\mathrm{OD}+\mathrm{D}$ reaction. Thereafter, evacuation under vacuum $(<20 \mathrm{mTorr})$ for a period of 4 hours at $150{ }^{\circ} \mathrm{C}$ was required to evacuate the water gas phase completely and avoid further reaction. Note that this temperature is not high enough to also remove the OD and D products of the dissociation reaction. Then, at room temperature, $\mathrm{CO}_{2}$ adsorption was measured again and the cell was evacuated as in step (i).

(iii) Formic acid production and removal: The temperature in the cell was raised back to $200{ }^{\circ} \mathrm{C}$ and 40 Torr of $\mathrm{CO}$ were introduced for 1 hour to start the formic acid production. Spectra were recorded. Thereafter, the cell was evacuated for 3 hours under vacuum $(<20 \mathrm{mTorr})$ at $200{ }^{\circ} \mathrm{C}$, removing the formic acid and unreacted $\mathrm{CO}$, while spectra were recorded. Then, $\mathrm{CO}_{2}$ adsorption at room temperature was measured and the cell was evacuated as in step (i). This production and removal step was repeated two times and we refer to each occurrence as removal 1 and removal 2.

\section{Computational Details}

$A b$ initio modeling was performed at the density functional theory level, using QUANTUM ESPRESSO ${ }^{57}$ with the vdW-DF functional. ${ }^{58} 61$ Ultrasoft pseudo potentials were used with cutoffs of $544 \mathrm{eV}$ and $5440 \mathrm{eV}$ for the wave functions and charge density. Due to the large dimensions of the unit cell, only the $\Gamma$-point was used. During relaxations all atom positions were optimized until forces were less than $2.6 \times 10^{-4} \mathrm{eV} / \AA$. Reaction barriers were found with a transition-state search algorithm, i.e. the climbing-image nudged-elastic band method $62[63$ The primitive cell of our pristine Zn-MOF-74 system contained 54 atoms and has space group $\mathrm{R} \overline{3}$. Additional atoms/molecules were added as appropriate for the reactants. The rhombohedral axes are $a=b=c=15.105 \AA$ and $\alpha=\beta=\gamma=117.78^{\circ}$. 32 


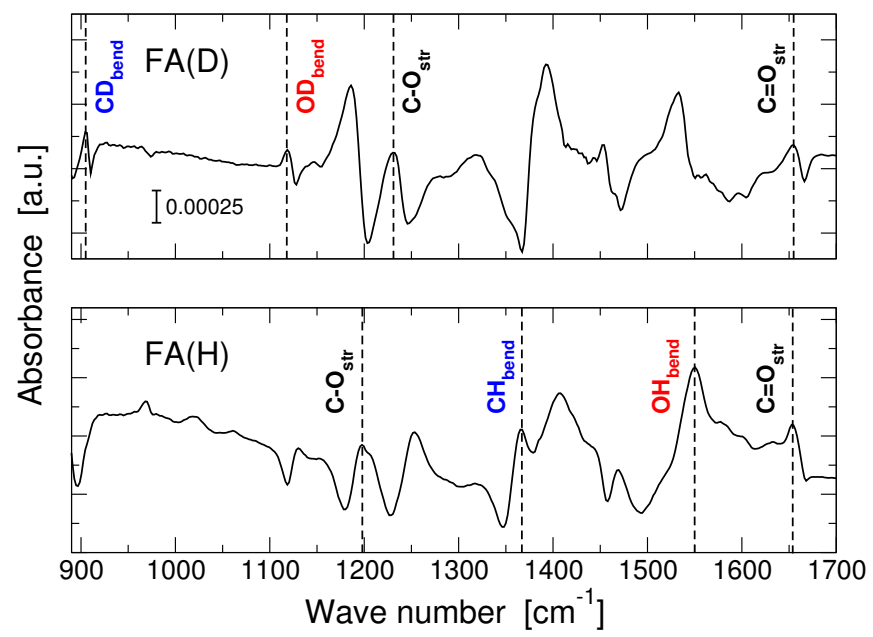

FIG. 2. IR absorption spectra of Zn-MOF-74 reacted with $\mathrm{D}_{2} \mathrm{O}$ (top panel) and $\mathrm{H}_{2} \mathrm{O}$ (bottom panel) followed by the addition of 40 Torr of $\mathrm{CO}$ for 1 hour at $200{ }^{\circ} \mathrm{C}$. The panels show the characteristic peaks of $\mathrm{FA}(\mathrm{D})$ and $\mathrm{FA}(\mathrm{H})$. Both samples are referenced to pure Zn-MOF-74.

\section{RESULTS AND DISCUSSION}

\section{A. Confirming Formic Acid Production and Removal}

We begin by showing experimental evidence that the reactive environment inside the MOF-74 channels catalyses the formic acid production (through water dissociation) $\mathrm{OH}+\mathrm{H}+\mathrm{CO} \rightarrow \mathrm{HCO}_{2} \mathrm{H}$ after the water dissociation $\mathrm{H}_{2} \mathrm{O} \rightarrow \mathrm{OH}+\mathrm{H}$ has taken place. To this end, we follow the three-step procedure outlined in Sec. IIC. After the introduction of CO in step (iii), our IR spectra in Fig. 2 clearly show the presence of FA(D) and FA(H) molecules ${ }^{[64}$ As expected, due to the deuterium presence, the $\mathrm{FA}(\mathrm{D})$ peaks $\left(\mathrm{CD}_{\text {bend }}\right.$ and $\left.\mathrm{OD}_{\text {bend }}\right)$ are red shifted with respect to $\mathrm{FA}(\mathrm{H})$ peaks $\left(\mathrm{CH}_{\text {bend }}\right.$ and $\left.\mathrm{OH}_{\text {bend }}\right)$ by a factor of $\sim 1.4$. $\mathrm{C}-\mathrm{O}$ and $\mathrm{C}=\mathrm{O}$ modes are less disturbed (shifted), as they are not directly affected by the presence of deuterium or hydrogen. The $\mathrm{OH}_{\text {bend }}$ vibrational mode signal at $\sim 1550 \mathrm{~cm}^{-1}$ for $\mathrm{FA}(\mathrm{H})$ appears very close to a strong MOF mode at $\sim 1530 \mathrm{~cm}^{-1}$, and this vibrational mode may be contributing to the $\mathrm{OH}_{\text {bend }}$ signal. On the other hand, the signal at $\sim 1530 \mathrm{~cm}^{-1}$ in the FA(D) spectrum may be due to a hydrogen contamination of the deuterated water, increased by the vibrations of the MOF modes.

In Fig. 3 we show how the characteristic peaks of FA(D) disappear as a function of time during the removal in step (iii), showing that the produced formic acid can readily be removed. Note that these experiments rely on the detection of the linker O-D mode at $970 \mathrm{~cm}^{-1}$ and are thus only performed for the deuterated case (see Sec. II B). We will henceforth only discuss the deuterated case. It is interesting to note that - while the starting point for removal 1 and 2 are comparable

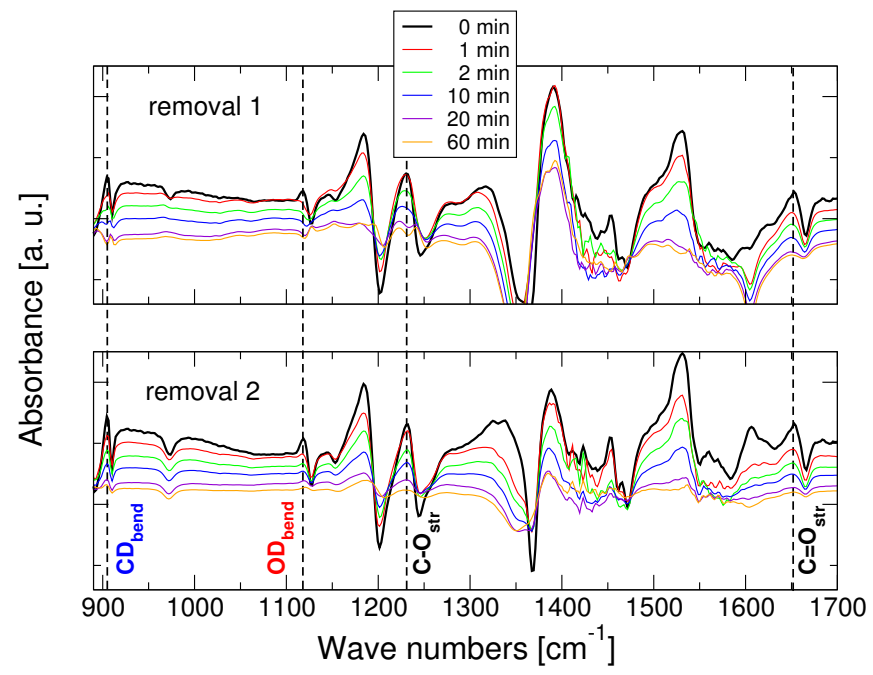

FIG. 3. IR spectra of the desorption of FA(D) as a function of time for removal 1 and removal 2. Both figures are referenced to pure Zn-MOF-74.

to within $6 \%$ - the desorption becomes faster. For example, in the former case $35 \%$ of $\mathrm{FA}(\mathrm{D})$ was removed after $20 \mathrm{~min}$, while in the latter $62 \%$ was removed during the same time. This fact, together with the fact that several removals are necessary to react all OD and D groups suggests a bottleneck in diffusion of the reactants and products, discussed further below.

After the water dissociation reaction happens, its products (OD or $\mathrm{OH}$ ) are strongly bound to primary adsorption site in the MOF and take up valuable adsorption sites. This undesirable decrease of the MOF's adsorption capacity is well known ${ }^{45 / 46 / 65}$ and unfortunately limits the applicability of MOF materials to non-humid environments. Note that the water dissociation products bind so strongly to the MOF that a simple removal through activation is not possible before the MOF disintegrates. Other means to recover the uptake capacity of MOFs after exposure to water are thus highly desirable. Our production and removal of formic acid reacts those unwanted groups that are otherwise bound to the MOF after the water dissociation reaction. We now show that this process also partially restores the MOF's small-molecule uptake capacity. In Fig. 4 we track the $970 \mathrm{~cm}^{-1}$ peak (a measure for the amount of dissociated heavy water present in the MOF cavity $\sqrt{45}$ as well as the $2338 \mathrm{~cm}^{-1}$ peak (a measurement of the $\mathrm{CO}_{2}$ adsorption capacity ${ }^{56}$ at different stages of our experiment. We see that the former decreases as we introduce $\mathrm{CO}$ into the system, i.e by $1.6 \%$ after removal 1 and $7.9 \%$ after removal 2. This confirms that we have successfully removed the D groups from the linkers of the MOF. On the other hand, the latter - after an expected big reduction in the $\mathrm{CO}_{2}$ uptake capacity after the $\mathrm{D}_{2} \mathrm{O}$ dissociation $(22 \%)$-increases by $1.5 \%$ and $5.1 \%$ after removal 1 and 2. While the MOF's uptake capacity recovery is relatively small per removal cycle, our results constitute 


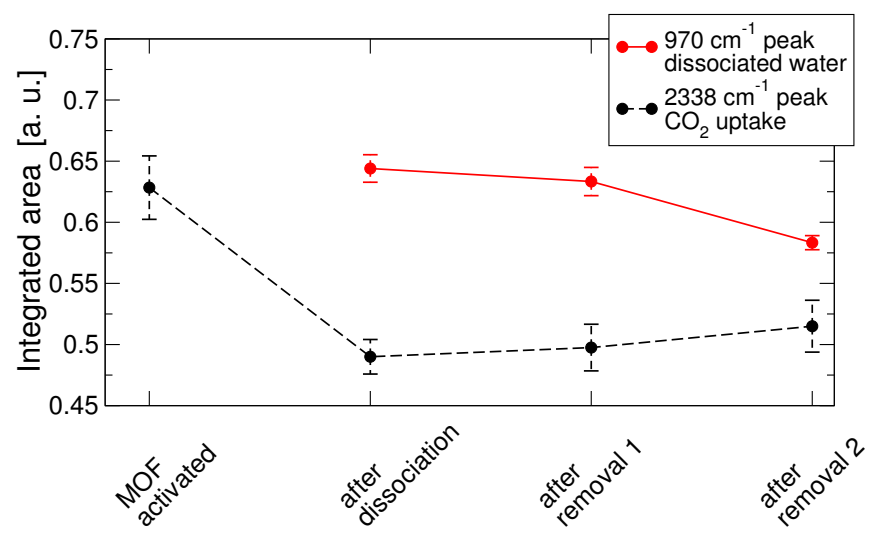

FIG. 4. Integrated areas of the $970 \mathrm{~cm}^{-1}$ peak (a measure of the amount of dissociated water) and $2338 \mathrm{~cm}^{-1}$ peak (a measure of the $\mathrm{CO}_{2}$ uptake capacity).

the first proof-of-principle that such a recovery is even possible.

As expected, the decrease in the amount of dissociated water (area under the peak at $970 \mathrm{~cm}^{-1}$ ) goes hand-inhand with the increase of the $\mathrm{CO}_{2}$ uptake capacity (area under the peak at $2338 \mathrm{~cm}^{-1}$ ). However, it is interesting to see that more than one removal cycle is necessary to restore a significant amount of uptake capacity. In principle, the partial pressure of 40 Torr CO introduced into the system should be more than enough (we estimate that it results in at least $6 \mathrm{CO}$ molecules per unit cell) to react all $\mathrm{OD}$ and $\mathrm{D}$ groups. However, this is not the case, see Fig 4. We conclude that the produced formic acid inhibits diffusion of CO deeper into the bulk. After each removal of formic acid and the renewed introduction of $\mathrm{CO}$, the process picks up where it had left off earlier, working from the MOF surface into the bulk until, eventually, all OD and D groups have been reacted. Work to reduce the number of cycles thus needs to focus on diffusion in MOF-74 66 as well as using similar reactions with different products.

The CO region in the IR spectrum also provides information on the mechanism of formic acid formation. Figure 5 shows the $\mathrm{CO}$ region during removal 1 at several stages. When $\mathrm{CO}$ gas is still inside the MOF, the predominant signal is at $2173 \mathrm{~cm}^{-1}$. However, after $1 \mathrm{~min}$ of desorption, a shift to lower frequencies $\left(2150 \mathrm{~cm}^{-1}\right)$ is observed. This indicates that the majority of the CO gas phase has been evacuated and now the IR spectrum is dominated by a signal that suggests a stronger interaction between the $\mathrm{CO}$ and the $\mathrm{MOF}$, such as in the $\mathrm{CO}_{2} \mathrm{H}+\mathrm{H}$ state (see Fig. 6). After longer periods of desorption, the intensity of the signal is reduced as the chamber is evacuated.

Before we continue to study the nature of the reaction, we give an estimate of how much formic acid is produced. From our calculations we know that the crystal density of Zn-MOF-74 is $1.231 \mathrm{~g} / \mathrm{mL}$, with a volume of $3944.65 \AA^{3}$ for the hexagonal cell (note that the hexag-

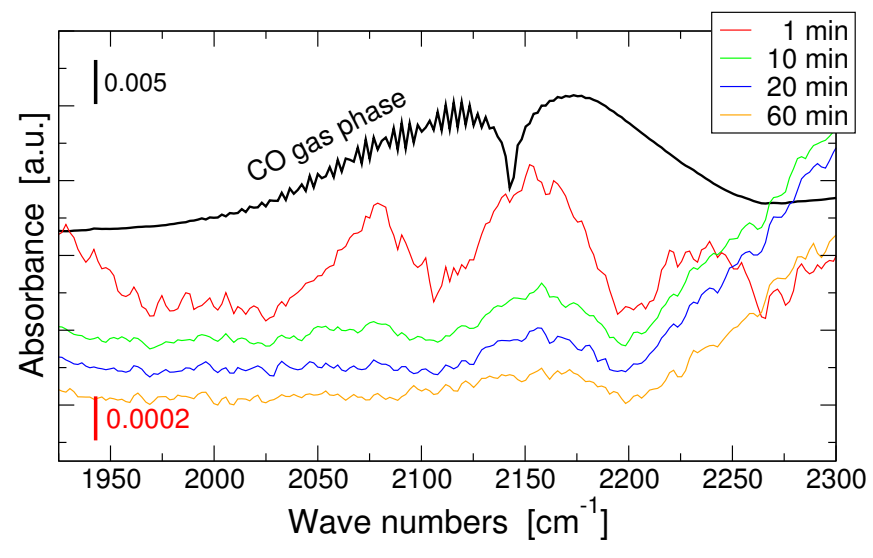

FIG. 5. CO region of the IR spectrum during removal 1. The black line is taken just before $\mathrm{CO}$ evacuation and is measured on a scale of 0.005 , since the CO gas-phase signal is very strong. Thereafter, IR spectra are taken at 1, 10, 20, and 60 minutes during evacuation, measured on the smaller scale of 0.0002 .

onal cell contains 18 metal centers and is three times bigger than the rhombohedral representation) ${ }^{32}$ Based on that, we calculate that in our sample ( $2 \mathrm{mg}$ of $\mathrm{Zn}-\mathrm{MOF}$ 74) we have $4.12 \times 10^{17}$ hexagonal unit cells. According to Fig. 4, we observe a reduction of $22 \%$ in the $\mathrm{CO}_{2}$ adsorption capacity, suggesting that we produced $\sim 4 \mathrm{OD}+\mathrm{D}$ groups every 18 metal centers. Therefore, when $\mathrm{CO}$ is introduced into the cell and $5.1 \%$ of the $\mathrm{CO}_{2}$ adsorption capacity is recovered, we estimate a production of $3.95 \times 10^{17}$ formic acid molecules. This corresponds to $2.311 \times 10^{-5} \mathrm{~mL}$ of formic acid in the $2 \mathrm{mg}$ of $\mathrm{Zn}-\mathrm{MOF}$ 74 , or $11.55 \mu \mathrm{L} / \mathrm{g}_{\mathrm{MOF}}$. Clearly, this is a small quantity, but as mention before, our goal is to investigate the chemistry in the confined spaces of Zn-MOF-74 and not the mass production of formic acid.

\section{B. Pathway of the Formic Acid Reaction}

We now investigate the nature of the formic acid reaction $\mathrm{H}_{2} \mathrm{O}+\mathrm{CO} \rightarrow \mathrm{HCO}_{2} \mathrm{H}$ and give and explanation of how it takes place. We know that the first step is the dissociation of water at the metal centers $\mathrm{H}_{2} \mathrm{O} \rightarrow \mathrm{OH}+\mathrm{H}$, which we have studied in detail before!44|45|65 We find that the water dissociation takes place above $150{ }^{\circ} \mathrm{C}$ with an energy barrier up to $1.09 \mathrm{eV}$, depending on the number of water molecules involved in the reaction. 65 The second step of the reaction starts by the introduction of $\mathrm{CO}$ at $200{ }^{\circ} \mathrm{C}$, which catalyses the $\mathrm{OH}+\mathrm{H}+\mathrm{CO} \rightarrow \mathrm{HCO}_{2} \mathrm{H}$ reaction. Based on this information, and taking into account that the metal centers are poisoned by the $\mathrm{OH}$ groups after the $\mathrm{H}_{2} \mathrm{O} \rightarrow \mathrm{OH}+\mathrm{H}$ reaction, we propose the following mechanism for the overall reaction: Once the $\mathrm{H}_{2} \mathrm{O} \rightarrow \mathrm{OH}+\mathrm{H}$ reaction takes place, the added $\mathrm{CO}$ molecules interact with the $\mathrm{OH}$ groups at the metal centers to form $\mathrm{CO}_{2} \mathrm{H}$ adsorbed at the metal center. There- 


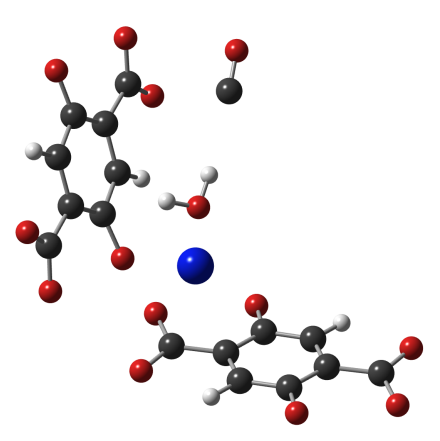

$\mathrm{H}_{2} \mathrm{O}+\mathrm{CO}$

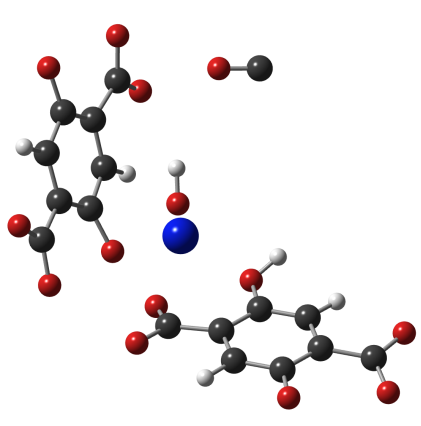

$\mathrm{OH}+\mathrm{H}+\mathrm{CO}$

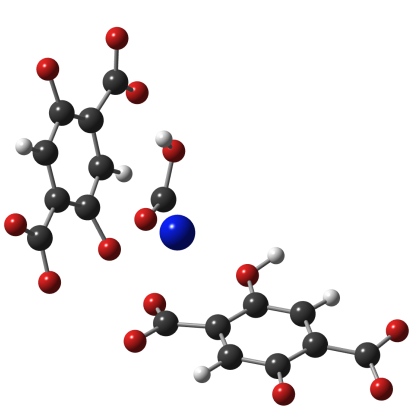

$\mathrm{CO}_{2} \mathrm{H}+\mathrm{H}$

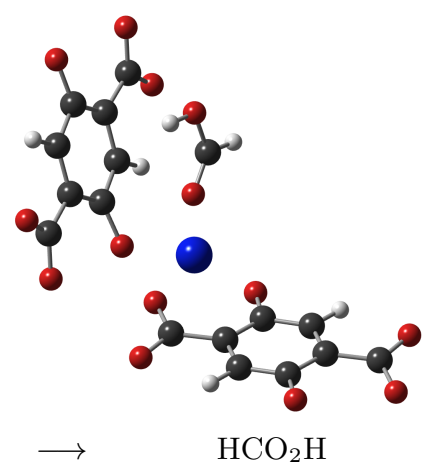

FIG. 6. Structures for the reactants $\left(\mathrm{H}_{2} \mathrm{O}+\mathrm{CO}\right)$, stable states $\left(\mathrm{OH}+\mathrm{H}+\mathrm{CO}, \mathrm{CO}_{2} \mathrm{H}+\mathrm{H}\right)$, and products $\left(\mathrm{HCO}{ }_{2} \mathrm{H}\right)$. First, the water is adsorbed at the open-metal site, while $\mathrm{CO}$ is adsorbed at a secondary site. Then, the water dissociates into $\mathrm{OH}+\mathrm{H}$; $\mathrm{OH}$ remains at the open-metal site and $\mathrm{H}$ is transferred to the $\mathrm{O}$ at the linker; $\mathrm{CO}$ is still adsorbed at the secondary site. Then, $\mathrm{CO}$ reacts with $\mathrm{OH}$ to form $\mathrm{CO}_{2} \mathrm{H}$ at the metal center. Finally, the $\mathrm{H}$ from the linker reacts with the $\mathrm{CO}_{2} \mathrm{H}$ to form $\mathrm{HCO}_{2} \mathrm{H}$ at the open-metal site.

after, the $\mathrm{CO}_{2} \mathrm{H}$ molecule interacts with the $\mathrm{H}$ at the linker to form formic acid $\mathrm{HCO}_{2} \mathrm{H}$. Overall, the reaction pathway follows $\mathrm{H}_{2} \mathrm{O}+\mathrm{CO} \rightarrow \mathrm{OH}+\mathrm{H}+\mathrm{CO} \rightarrow \mathrm{CO}_{2} \mathrm{H}+\mathrm{H}$ $\rightarrow \mathrm{HCO}_{2} \mathrm{H}$, as depicted in Fig. 6 .

We now use our $a b$ initio transition-state search to find the energetically most favorable pathway (i.e. lowest energy barriers) for our proposed reaction pathway. Results for the structures of reactants, stable states, and products are depicted in Fig. 6 and the energy profile along the entire reaction is plotted in Fig. 7. The first step of the reaction is the endothermic water dissociation $\mathrm{H}_{2} \mathrm{O}+\mathrm{CO} \rightarrow \mathrm{OH}+\mathrm{H}+\mathrm{CO}$. We have previously calculated its reaction barrier $(1.09 \mathrm{eV})$ and confirmed the separate $\mathrm{OH}$ (bound to the open-metal site) and $\mathrm{H}$ (bound to the $\mathrm{O}$ of the linker) experimentally inside MOF-74 above $150{ }^{\circ} \mathrm{C} 45$ Thereafter, the reaction proceeds exothermic via $\mathrm{OH}+\mathrm{H}+\mathrm{CO} \rightarrow \mathrm{CO}_{2} \mathrm{H}+\mathrm{H} \rightarrow \mathrm{HCO}_{2} \mathrm{H}$, resulting in the formation of formic acid adsorbed on the metal centers of Zn-MOF-74. Our calculations show that the energy barrier between the states $\mathrm{OH}+\mathrm{H}+\mathrm{CO}$ and $\mathrm{CO}_{2} \mathrm{H}+\mathrm{H}$ is $0.8 \mathrm{eV}$, while the barrier between $\mathrm{CO}_{2} \mathrm{H}+\mathrm{H}$ and $\mathrm{HCO}_{2} \mathrm{H}$ is $1.04 \mathrm{eV}$. The final state, i.e. $\mathrm{HCO}_{2} \mathrm{H}$, has an energy $0.23 \mathrm{eV}$ lower than the energy of the initial state $\mathrm{H}_{2} \mathrm{O}+\mathrm{CO}$, and the formic acid binds to the metal centers with an energy of $0.68 \mathrm{eV}(65.61 \mathrm{~kJ} / \mathrm{mol})$, comparable to the binding of other molecules to Zn-MOF-74.6[69 Thus, removal of the formic acid product from the openmetal sites can proceed through simple activation of the sample, as confirmed in Fig 3

The overall barrier for the reaction in Fig. 7 is significant and explains why only a small amount of formic acid is produced. But, that barrier corresponds to the presence of only one water molecule. In related work, we show that the barrier to the first step of the reaction is lowered by $37 \%$ when the water molecules create clusters above the linkers $\frac{65}{6 t}$ is conceivable that the presence of several $\mathrm{CO}$ and/or $\mathrm{H}_{2} \mathrm{O}$ molecules can also lower the energy barrier of the $\mathrm{OH}+\mathrm{H}+\mathrm{CO} \rightarrow \mathrm{HCO}_{2} \mathrm{H}$ reaction. However, due to the large number of stable geometries

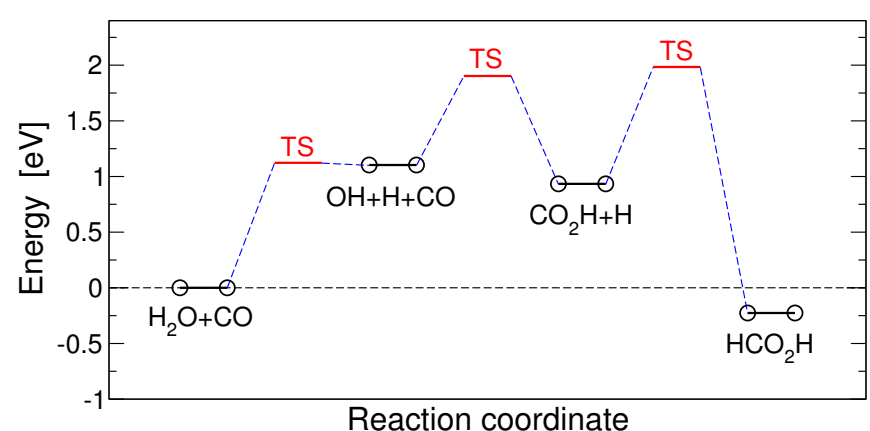

FIG. 7. Energy of the stable and transition states (TS) along the $\mathrm{H}_{2} \mathrm{O}+\mathrm{CO} \rightarrow \mathrm{HCO}_{2} \mathrm{H}$ reaction.

and possible paths for the $\mathrm{H}_{2} \mathrm{O}+\mathrm{CO} \rightarrow \mathrm{HCO}_{2} \mathrm{H}$ reaction when more than one molecule is involved, a comprehensive $a b$ initio transition-state search becomes computational prohibitively expensive.

\section{CONCLUSIONS}

Our experimental and theoretical work confirms that we can use the $\mathrm{OH}$ and $\mathrm{H}$ groups - produced by the $\mathrm{H}_{2} \mathrm{O} \rightarrow \mathrm{OH}+\mathrm{H}$ reaction - to start a new reaction mechanism catalyzed inside the confined environment of the Zn-MOF-74 channels through water dissociation and produce formic acid via $\mathrm{H}_{2} \mathrm{O}+\mathrm{CO} \rightarrow \mathrm{HCO}_{2} \mathrm{H}$. This discovery has several important consequences: It opens the door to a new set of catalytic reactions inside a well controlled system (MOF-74), it provides a proof-of-principle that a recovery of the adsorption capacity and structural stability of Zn-MOF-74 is possible after exposure to water, and finally it produces the important medical/industrial feedstock formic acid. 


\section{ACKNOWLEDGEMENTS}

This work was supported by DOE Grant No. DEFG02-08ER46491. Furthermore, this research used com- putational resources of the OLCF at ORNL, which is supported by DOE grant DE-AC05-00OR22725.
* thonhauser@wfu.edu

1 J. Liu, P. K. Thallapally, B. P. McGrail, D. R. Brown, and J. Liu, Chem. Soc. Rev. 41, 2308 (2012)

2 L. J. Murray, M. Dinca, and J. R. Long, Chem. Soc. Rev. 38, 1294 (2009)

J.-R. Li, Y. Ma, M. C. McCarthy, J. Sculley, J. Yu, H.-K. Jeong, P. B. Balbuena, and H.-C. Zhou, Coord. Chem. Rev. 255, 1791 (2011)

${ }^{4}$ S. Qiu and G. Zhu, Coord. Chem. Rev. 253, 2891 (2009)

5 N. Nijem, H. Wu, P. Canepa, A. Marti, K. J. Balkus, T. Thonhauser, J. Li, and Y. J. Chabal, J. Am. Chem. Soc. 134, 15201 (2012).

${ }^{6}$ K. Lee, J. D. Howe, L.-C. Lin, B. Smit, and J. B. Neaton, Chem. Mater. 27, 668 (2015)

7 D. Zhao, D. Yuan, and H.-C. Zhou, Energy Environ. Sci. 1, $222(2008)$

${ }^{8}$ N. L. Rosi, J. Eckert, M. Eddaoudi, D. T. Vodak, J. Kim, M. O'Keeffe, and O. M. Yaghi, Science 300, 1127 (2003)

9 H. Wu, Q. Gong, D. H. Olson, and J. Li, Chem. Rev. 112, $836(2012)$

${ }^{10}$ Y. He, W. Zhou, G. Qian, and B. Chen, Chem. Soc. Rev. 43, $5657(2014)$

${ }^{11}$ L. E. Kreno, K. Leong, O. K. Farha, M. Allendorf, R. P. Van Duyne, and J. T. Hupp, Chem. Rev. 112, 1105 (2012).

12 P. Canepa, K. Tan, Y. Du, H. Lu, Y. J. Chabal, and T. Thonhauser, J. Mater. Chem. A 3, 986 (2015).

13 C. Serre, C. Mellot-Draznieks, S. Surblé, N. Audebrand, Y. Filinchuck, and G. Férey, Science 315, 1828 (2007)

${ }^{14}$ M. D. Allendorf, R. J. T. Houk, L. Andruskiewicz, A. A. Talin, J. Pikarsky, A. Choundhury, K. A. Gall, and P. J. Hensketh, J. Am. Chem. Soc. 130, 14404 (2008)

15 J.-C. Tan and A. K. Cheetham, Chem. Soc. Rev. 40, 1059 (2011)

Io Z. Hu, B. J. Deibert, and J. Li, Chem. Soc. Rev. 43, 5815 (2014)

${ }^{17}$ T. Uemura, N. Yanai, and S. Kitagawa, Chem. Soc. Rev. 38, $1228(2009)$

${ }^{18}$ M. J. Vitorino, T. Devic, M. Tromp, G. Férey, and M. Visseaux, Macromol. Chem. Phys. 210, 1923 (2009)

19 M. D. Allendorf, C. A. Bauer, R. K. Bhakta, and R. Houk, Chem. Soc. Rev. 38, 1330 (2009)

20 K. A. White, D. A. Chengelis, K. A. Gogick, J. Stehman, N. L. Rosi, and S. Petoud, J. Am. Chem. Soc. 131, 18069 (2009)

21 S. Bordiga, C. Lamberti, G. Ricchiardi, L. Regli, F. Bonino, A. Damin, K.-P. Lillerud, M. Bjorgen, and A. Zecchina, Chem. Commun. , 2300 (2004)

${ }^{22}$ M. Kurmoo, Chem. Soc. Rev. 38, 1353 (2009)

23 P. Horcajada, T. Chalati, C. Serre, B. Gillet, C. Sebrie, T. Baati, J. Eubank, D. Heurtaux, P. Clayette, C. Kreuz, J.-S. Chang, Y. Hwang, V. Marsaud, P.-N. Bories, L. Cynober, S. Gil, G. Férey, P. Couvreur, and R. Gref, Nat. Mater. 9, 172 (2010)

24 A. Stroppa, P. Jain, P. Barone, M. Marsman, J. M. PerezMato, A. K. Cheetham, H. W. Kroto, and S. Picozzi,
Angew. Chem., Int. Ed. 50, 5847 (2011)

25 A. Stroppa, P. Barone, P. Jain, J. M. Perez-Mato, and S. Picozzi, Adv. Mater. 25, 2284 (2013).

${ }^{26}$ D. Di Sante, A. Stroppa, P. Jain, and S. Picozzi, J. Am. Chem. Soc. 135, 18126 (2013).

27 C.-D. Wu and W. Lin, Angew. Chem. Int. Ed. 46, 1075 (2007)

28 J. Lee, O. K. Farha, J. Roberts, K. A. Scheidt, S. T. Nguyen, and J. T. Hupp, Chem. Soc. Rev. 38, 1450 (2009).

${ }^{29}$ R.-Q. Zou, H. Sakurai, and Q. Xu, Angew. Chemie Int. Ed. 45, 2542 (2006)

su I. Luz, F. X. Llabrés i Xamena, and A. Corma, J. Catal. 276, 134 (2010).

31 Y. Liu, H. Kabbour, C. M. Brown, D. A. Neumann, and C. C. Ahn, Langmuir 24, 4772 (2008)

${ }^{32}$ W. Zhou, H. Wu, and T. Yildirim, J. Am. Chem. Soc. 130, 15268 (2008).

ss H. Wu, J. M. Simmons, G. Srinivas, W. Zhou, and T. Yildirim, J. Phys. Chem. Lett. 1, 1946 (2010).

${ }^{34}$ P. D. C. Dietzel, R. E. Johnsen, H. Fjellvåg, S. Bordiga, E. Groppo, S. Chavan, and R. Blom, Chem. Commun., $5125(2008)$

35 S. R. Caskey, A. G. Wong-Foy, and A. J. Matzger, J. Am. Chem. Soc. 130, 10870 (2008).

36 L. Valenzano, B. Civalleri, S. Chavan, G. T. Palomino, C. O. Areán, and S. Bordiga, J. Phys. Chem. C 114, 11185 (2010)

3 H. Wu, W. Zhou, and T. Yildirim, J. Am. Chem. Soc. 131, 4995 (2009).

38 P. Valvekens, M. Vandichel, M. Waroquier, V. Van Speybroeck, and D. De Vos, J. Catal. 317, 1 (2014).

39 H.-F. Yao, Y. Yang, H. Liu, F.-G. Xi, and E.-Q. Gao, J. Mol. Catal. A: Chem 394, 57 (2014).

${ }^{40}$ T. Kim, D. H. Kim, S. Kim, Y. D. Kim, Y.-S. Bae, and C. Y. Lee, Polyhedron 90, 18 (2015).

41 D. Sun, F. Sun, X. Deng, and Z. Li, Inorg. Chem. 54, 8639 (2015).

${ }^{42}$ Y. Zhang, Y. Liu, X. Zhang, Y. Li, M. Gao, and H. Pan, J. Phys. Chem. C 119, 24760 (2015).

43 D. Ruano, M. Díaz-García, A. Alfayate, and M. SánchezSánchez, Chem. Cat. Chem. 7, 674 (2015).

44 S. Zuluaga, E. M.-A. Fuentes-Fernandez, K. Tan, F. Xu, J. Li, Y. J. Chabal, and T. Thonhauser, J. Mater. Chem. A 4, 5176 (2016).

${ }^{45}$ K. Tan, S. Zuluaga, Q. Gong, P. Canepa, H. Wang, J. Li, Y. J. Chabal, and T. Thonhauser, Chem. Mater. 26, 6886 (2014)

${ }^{46}$ K. Tan, N. Nijem, Y. Gao, S. Zuluaga, J. Li, T. Thonhauser, and Y. J. Chabal, CrystEngComm 17, 247 (2015).

47 X. Gu, Z.-H. Lu, H.-L. Jiang, T. Akita, and Q. Xu, J. Am. Chem. Soc 133, 11822 (2011)

${ }^{48}$ K. Tedsree, T. Li, S. Jones, C. Wong, A. Chan, K. M. K. Yu, P. A. J. Bagot, E. A. Marquis, G. D. W. Smith, and S. C. E. Tsang, Nature Nanotech. 6, 302 (2011) 
49 T. Zell, B. Butschke, Y. Ben-David, and D. Milstein, Chem. Eur. J. 19, 25 (2013)

50 S. Zhang, A. Metin, D. Su, and S. Sun, Angew. Chem. Int. Ed. 52, 3681 (2013).

51 F. Joó, ChemSusChem 1, 805 (2008).

${ }^{52}$ S. Ha, Z. Dunbar, and R. I. Masel, J. Power Sources 158, 129 (2006)

53 J. Chang, L. Feng, C. Liu, W. Xing, and X. Hu, Angew. Chem. Int. Ed. 53, 122 (2014).

${ }_{54}$ L. Shen, H. Li, L. Lu, Y. Luo, Y. Tang, Y. Chen, and T. Lu, Electrochim. Acta 89, 497 (2013)

${ }^{55}$ L. Feng, L. Yan, Z. Cui, C. Liu, and W. Xing, J. Power Sources 196, 2469 (2011)

5o Y. Yao, N. Nijem, J. Li, Y. J. Chabal, D. C. Langreth, and T. Thonhauser, Phys. Rev. B 85, 064302 (2012)

57 P. Giannozzi, S. Baroni, N. Bonini, M. Calandra, R. Car, C. Cavazzoni, D. Ceresoli, G. L. Chiarotti, M. Cococcioni, I. Dabo, A. Dal Corso, S. de Gironcoli, S. Fabris, G. Fratesi, R. Gebauer, U. Gerstmann, C. Gougoussis, A. Kokalj, M. Lazzeri, L. Martin-Samos, N. Marzari, F. Mauri, R. Mazzarello, S. Paolini, A. Pasquarello, L. Paulatto, C. Sbraccia, S. Scandolo, G. Sclauzero, A. P. Seitsonen, A. Smogunov, P. Umari, and R. M. Wentzcovitch, J. Phys. Condens. Matter 21, 395502 (2009).

58 T. Thonhauser, S. Zuluaga, C. A. Arter, K. Berland, E. Schröder, and P. Hyldgaard, Phys. Rev. Lett. 115, 136402 (2015).
${ }^{59}$ K. Berland, V. R. Cooper, K. Lee, E. Schröder, T. Thonhauser, P. Hyldgaard, and B. I. Lundqvist, Rep. Prog. Phys. 78, 066501 (2015)

कo D. C. Langreth, B. I. Lundqvist, S. D. Chakarova-Käck, V. R. Cooper, M. Dion, P. Hyldgaard, A. Kelkkanen, J. Kleis, L. Kong, S. Li, P. G. Moses, E. D. Murray, A. Puzder, H. Rydberg, E. Schröder, and T. Thonhauser, J. Phys. Condens. Matter 21, 084203 (2009).

61 T. Thonhauser, V. R. Cooper, S. Li, A. Puzder, P. Hyldgaard, and D. C. Langreth, Phys. Rev. B 76, 125112 (2007)

${ }^{\circ 2}$ G. Henkelman, B. P. Uberuaga, and H. Jónsson, J. Chem. Phys. 113, 9901 (2000)

${ }^{63}$ G. Henkelman and H. Jónsson, J. Chem. Phys. 113, 9978 (2000)

${ }^{64}$ R. C. Millikan and K. S. Pitzer, J. Am. Chem. Soc. 80, 3515 (1958).

o5 S. Zuluaga, E. M. A. Fuentes-Fernandez, K. Tan, J. Li, Y. J. Chabal, and T. Thonhauser, J. Mater. Chem. A (2016), 10.1039/C6TA02501C, in print.

oo P. Canepa, N. Nijem, Y. J. Chabal, and T. Thonhauser, Phys. Rev. Lett. 110, 026102 (2013)

67 D.-J. Lee, D.-J. Li, H. Kim, and K. Lee, Microporous Mesoporous Mater. 163, 169 (2012)

${ }^{\circ}$ L.-C. Lin, J. Kim, X. Kong, E. Scott, T. M. McDonald, J. R. Long, J. A. Reimer, and B. Smit, Angew. Chem. Int. Ed. 52, 1521 (2013).

oิ P. Canepa, C. A. Arter, E. M. Conwill, D. H. Johnson, B. A. Shoemaker, K. Z. Soliman, and T. Thonhauser, J. Mater. Chem. A 1, 13597 (2013) 